\title{
A conversation with Charles Sawyers
}

C harles Sawyers of Memorial Sloan Kettering Cancer Center has defined the molecular lesions that cause cancer and used these insights to develop new drugs. Specifically, Sawyers (Figure 1) was one of the critical members of the team that brought imatinib and dasatinib to bear on chronic myeloid leukemia (CML). Furthermore, his work has identified second-generation antiandrogen drugs to treat castration-resistant prostate cancer. Watch the full interview on https://jci.org/videos/ cgms to hear the personal stories of a physician-scientist called "the greatest cancer researcher of our time" by one of his peers.

JCI: Can you tell me a little about your upbringing?

Sawyers: I grew up in Nashville, Tennessee, the child of two physicians. My father was a surgeon and rose through the ranks at Vanderbilt to be the chairman of surgery. My mother was an anesthesiologist. I had three uncles who were physicians and a grandfather who was a physician. I tried to resist becoming a physician a little bit.

I was a brainy kid and especially liked math and science, but I also played competitive tennis all through high school. I decided to head to Princeton for college because I wanted to spread my wings. I found that I really liked taking liberal arts classes and decided to major in history. I wasn't dead set on going to medical school, but I thought I probably would, so my strategy was, take the requirements as an "in case" and explore other things, and the history department at Princeton is outstanding.

I had the somewhat unique opportunity, through my dad, to visit China in 1980. Shortly after Nixon made a trip to China, it opened the gates and I was part of one of the early American trips and found it incredibly interesting. It sparked an interest in public health and the way medicine is organized, which was part of what I was initially interested in when I started medical school.

JCI: At what point did you find the scientific side of medicine?

Sawyers: In the second year of medical school at Hopkins, we were taught about

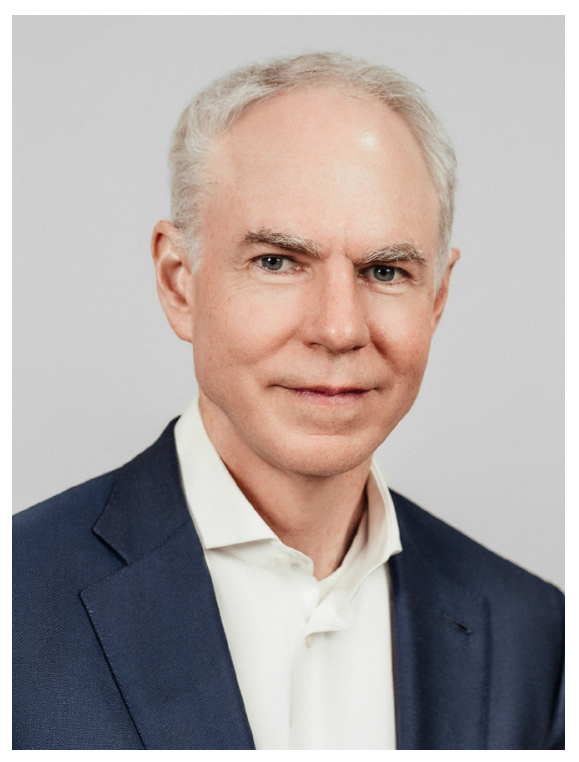

Figure 1. Charles Sawyers in New York City on March 2, 2018. Image credit: Alexey Levchenko.

disease by physicians who had labs, and that is when the spark was lit. I remember different lectures where I suddenly felt there existed a whole world that I didn't know anything about that maybe I dismissed too early. I can remember a lecture on the structure of hemoglobin and the understanding of the sickle-cell mutations, and the ability to reduce a complex disease down to a point mutation in one gene fascinated me.

I was able to forgo many of the electives of the fourth year and spent a year in a pharmacology lab, getting exposure to experimental design. I met a new community of postdocs and graduate students.

JCI: But at the same time, you weren't willing to give up medicine, heading west for a residency in internal medicine.

Sawyers: I went to UCSF because my older cousin, who had also gone to Hopkins, was a rheumatology fellow and working in a basic immunology lab and he said, "You've got to come out here. It's unbelievable." I was avidly reading everything about molecular medicine and there was, at that time, an incredible community of physicians who were MD-scientists at UCSF - Harold Varmus and Mike Bishop - to name just two. It ended up being a transformative experience.

Joel Ernst was my attending when I was a resident. I got to know him, and we just clicked. I was able to parlay roughly six months of the third year of residency into a research experience in his lab. I agreed to cover the medical ICU at night at San Francisco General Hospital while I worked in Joel's lab during the day. It was a pretty grueling night schedule, but it was totally worth it to me: I got to have my cake and eat it too. We were cloning genes involved in white blood cell phagocytosis of bacteria.

JCI: At what point did you turn towards hematology/oncology?

Sawyers: Oncogenes were being described, the Bishop/Varmus thesis was starting to gather momentum, and I just knew that something big was here. I knew it was what I wanted to do clinically when I was on the leukemia service at Moffitt Hospital [UCSF]. To frame the timing, this was when allogeneic bone marrow transplantation was relatively new. CML was a disease in which bone marrow transplant was really starting to show exciting outcome data.

I read all of the early papers from Nowell and Hungerford on the description of the Philadelphia chromosome (BCR-ABL). And then Janet Rowley's discovery, through cytogenetic banding, that BCR-ABL resulted from a reciprocal translocation and the further race to clone the translocation. Joel pointed me to a paper from Owen Witte wherein he cloned the translocation and had the first cDNA. I contacted Owen as a thirdyear resident to see if I could do research in his lab. I had to get out a typewriter and write a letter and put a stamp on the envelope and mail it. And he wrote me back and said, "Call me." We were able to work it out so that I started in his lab before I started my clinical fellowship.

The timing was very serendipitous with the recent invention of PCR. Our question was, could you detect the BCR-ABL transcript by PCR? That was a pretty novel idea back then. Owen let me work through one of the technicians to keep the project going when I started in the clinic, knowing I would have all the connections and access to the samples from patients that would make this story into something important. We pub- 
lished a nice paper showing you could track low levels of transcripts in patients who had had an allogeneic transplant. The prognostic impact was not clear at that time, but now it's a standard test.

JCI: When did you meet Brian Druker?

Sawyers: Early in my postdoc, Owen trusted me enough to represent the lab at meetings. And Brian was in Tom Robert's group and then Jim Griffin's group at the Farber. We were basically at equivalent stages and clicked because of our backgrounds; Brian had also gotten an MD with no real prior research experience until he was a postdoc. We stayed close when we each got our jobs, Brian at Oregon Health Sciences University.

Brian invited me as a guest speaker to OHSU in the early ' 90 s and showed me data with a compound [STI-571, later called imatinib mesylate/Gleevec] that Nick Lydon and colleagues had sent him from Ciba-Geigy Pharmaceuticals [now Novartis]. It looked pretty interesting, but it was very hard at that stage to know if we should put in a big effort. He asked me to help him champion the idea, and that began a long, extremely fruitful collaboration.

JCI: What was it like as you were getting the data from the dose-escalation trials?

Sawyers: We didn't want to get too ahead of ourselves in terms of excitement. Like any phase I trial in cancer, it was a classic $3+3$ dose escalation, where three patients receive the initial starting (very low) dose, and nothing happened. There was actually a hint at the next dose level that one patient's white blood cell count seemed to get better. At the next dose level, all three patients had a decline in their white blood cell count.

The real test of true benefit in CML is to test the bone marrow for the presence of BCR-ABL. Those results started coming in after patients had been on active doses for six months. I was lucky enough to have the first patient who had a complete cytogenetic remission. I remember this because I was in my office on a Saturday morning getting ready later that day to fly to a meeting in Europe, where Brian and I were going to discuss the first clinical data with Novartis. Back then, we would get the results from the cytogenetic analysis on the fax machine. My fax machine started whirring, and there was this report that showed 0 out of 20, and I could not believe it. I called the lab to make sure, and then I called Brian, but he had already left for the airport, so I didn't have anyone to call. So I actually called the patient, who lived in Santa Barbara - still does - and then I went to the airport.

JCI: Did you have some champagne on the flight?

Sawyers: I had some champagne with Brian and colleagues the next day. But one is only one, and it took a few more months for the rest of the data to come in, and it was amazing. After we saw the clinical benefit in chronic-phase CML patients, we opened the trial to patients with blast crisis - a phase of the disease that is lethal within months. It was incredible how many patients who were near death's door went into a complete remission within a matter of weeks of taking this pill.

JCI: Some of your patients relapsed.

Sawyers: Not only were they relapsing, they relapsed very quickly. I felt like we had to understand resistance as quickly as possible; I was aware enough of the euphoria of success and the agony of defeat. I catalyzed my lab group to make understanding resistance the highest priority project. Mercedes Gorre and Neil Shah were critical in discovering that resistance was caused by new mutations in the BCR-ABL kinase domain. We got it right, but we oversimplified; we sequenced 13 patients, and 11 of 13 had the same mutation, so we thought there was only one resistance mechanism. But with more analysis and more patients, it quickly became clear that there were numerous mutations that could all confer resistance.

In a stroke of good timing, John Kuriyan's lab had just solved the first ABL crystal structure. We decided to share data and had people from our groups meet to review data. We went up to see them and mapped out all the mutations using the software that they had to view structures. It became clear that the mutations were changing the conformational flexibility of the kinase. Imatinib is very special in how it binds ABL: ABL has to be in a conformation that's completely inactive, which it flips in and out of for a microsecond. What a lot of the new mutations did was prevent it from being so flexible. The idea was to find an inhibitor that could tolerate other conformations, and dasatinib is that drug.

JCI: During this time, you had also turned your attention to prostate cancer.

Sawyers: The prostate decision was influenced by a number of variables. One was, there was a urologist's lab right next to mine. This person needed some help, and I was a young assistant professor, and as I learned more about it, I got pretty interested in the idea of why hormone therapy works and why it stops working. I made a conscious effort to go to meetings of other disease areas and try to gauge the status of the big questions in the fields. And prostate cancer attracted me the most.

The first paper we published in prostate cancer described a whole new set of models, the equivalent of what we now call patient-derived xenografts, which we would grow in male mice, and then we would castrate the mouse and the tumor would regress and then regrow. These were much better than the existing three cell lines, two of which no longer expressed the androgen receptor. It seems obvious in retrospect that the androgen receptor must still be working in what's now called castration-resistant disease. But it was not a popular idea at the time, and no one was trying to develop better androgen-therapy drugs. The long and short of it is a project that was supposed to discover a multitude of different resistance mechanisms ended up pointing to the androgen receptor.

At the time we started this, I had developed a little bit of street cred in drug development, having done imatinib and dasatinib, but I really didn't know how to make a drug. I knew enough people to talk to pharma, but to them, this was such a yesterday idea and everyone had moved on to kinase inhibitors. At one point, we just said, we had to do it ourselves. I worked with UCLA chemist Michael Jung and a postdoctoral fellow, Samedi Ouk, and we had a welldesigned cell-based screen where we knew exactly the activity profile that a compound that could solve this had to have, because the drug that existed at the time called bicalutamide could be overcome by overexpressing the androgen receptor. It seems simple now, but we just recreated that context, made a high-throughput screening platform, and out came enzalutamide.

JCI: If you couldn't be a physician or a scientist, what do you think could have captivated you all these years?

Sawyers: I feel like I'm an academic at heart. I would've probably been a journal editor, as I love reading - I love writing. I like just talking about ideas.

\section{Ushma S. Neill}

